\title{
S. МИГРАШИЯ И АДАПТАШИЯ
}

В.В. Бубликов

\section{ИСЛАМИЗАЦИЯ ЕВРОПЫ КАК СЛЕДСТВИЕ ДЕХРИСТИАНИЗАЦИИ И ДЕМОГРАФИЧЕСКОГО КРИЗИСА}

\begin{abstract}
Аннотация: В статье анализируются причины и последствия охвативщего европейский континент процесса «исламизации». Сопоставление сочиологических данных, характеризующих уровень религиозности в европейских странах, России и США показывает, что «исламизачия» Европь-следствие дехристианизаџии и демографического кризиса. Рост мусульманского сообщества в европейских странах, численность которого уже превысила 44 млн. человек, будет продолжаться и в будущем благодаря высокому уровню рождаемости в мусульманских семьях и иммиграиии. Предполагается, что наиболее гармоничным решением проблемы конфликтности взаимоотношений коренных европейцев и сообщества европейских мусульман, может стать возрождение христианских ценностей и морали в среде коренных европейцев, что приведёт к улучшению демографической ситуации u, как следствие, отказу от массового приёма иммигрантов. Кроме того, ренессанс христианства в Европе позволит улучшить взаимоотношения двух сообществ (христиан и мусульман) используя исламский догмат о возможности мирного сосуществования с представителями иных монотеистических конфессий.
\end{abstract}

Ключевые слова: Сочиология, демография, кризис, мусульмане, христиане, исламизачия, секуляризация, европа, семья, иенности

$\Pi$ роблема исламизации европейского культурного, политического и общественного пространства возникла на повестке дня по историческим меркам недавно. Вопросы интеграции сообществ мусульман, а также непрерывный и бурный рост их численности, регулярно появляются в заголовках новостей и периодической печати, особенно после участившихся столкновений, в той или иной европейской стране, мусульманской молодёжи с праволиберальными политическими силами или полицией.

Причину напряжённых взаимоотношений небольшого, но активного и зачастую агрессивного мусульманского населения Европы с «христианским» большинством, одни видят в проявлении пресловутого «столкновения цивилизаций», другие, в нежелании мусульман подстроится под «стандарт» секулярной жизни европейцев. Однако такие ответы оказываются поверхностными.

Европа, на протяжении многих столетий своей истории, была моноконфессиональным, христианским регионом (за исключением некоторых окраинных ре- гионов континента, таких как южная Испания или Балканы). Полное доминирование христианской религии, разумеется, не исключало тяжелых и, часто, кровавых конфликтов и распрей на религиозной почве между субконфессиональными внутрихристианскими группами католиков, протестантов и православных. Однако эти конфликты чаще всего были определены логикой развития христианской церкви и, кроме того, они никогда не принимали таких форм, которые присущи современному противостоянию фундаменталистского сообщества европейских мусульман и «христианского» большинства европейского населения.

Так или иначе, но почти за две тысячи лет своей истории Европа была практически полностью христианской, причём не только с социологической точки зрения (численного доминирования христиан), но и с культурной, и с политической. Представители некоторых иных религиозных групп (например, иудеи) также присутствовавшие в социокультурной европейской среде были, во-первых, немногочисленны, а, вовторых, они, как правило, не предпринимали попыток 


\section{Политика и общество 4 (100) • 2013}

вмешательства в политические дела европейцев-христиан (по крайней мере до XIX столетия), впрочем, последние этого и не позволяли делать.

На таком фоне исключительной моноконфессиональности европейского социума (если не принимать во внимание внутрихристианские ветви), во второй половине XX века, за очень короткий, по историческим меркам, период времени (время жизни одногодвух поколений), в Европе появилось и выросло крупное мусульманское сообщество, численность которого только в странах Западной Европы сейчас оценивается в 18 млн. человек ${ }^{1}$. При этом практически сульман приходится на наиболее высокоразвитые страны Западной Европы. В то время как в странах с традиционно высокой долей мусульманского населения, например на Балканах, этот прирост незначителен. В таблице 1, представлены данные об оценочной доле мусульманского населения в европейских странах в 19902010 гг., а также прогноз на 2030 г. По этим данным за сорокалетний период 1990-2030 гг. доля приверженцев ислама, например во Франции возрастёт с 1\% до 10\%, в Германии с $3 \%$ до 7\%, в Великобритании с $2 \%$ до $8 \%$. Растёт доля мусульман и в населении России: 9\% в 1990 г., $12 \%$ в 2010 г., 14\% в 2030 г. ${ }^{3}$

Таблицуа 1. Доля мусульман в населении некоторых европейских стран 1990-2030 г2., \%

\begin{tabular}{|l|c|c|c|}
\hline \multicolumn{1}{|c|}{ СТРАНА } & 1990 г. & 2010 г. & 2030 г. \\
\hline Россия & $\mathbf{9 , 2}$ & $\mathbf{1 1 , 7}$ & $\mathbf{1 4 , 4}$ \\
\hline Украина & 0,2 & 0,9 & 1,0 \\
\hline Финляндия & 0,2 & 0,8 & 9,9 \\
\hline Швеция & 1,7 & 4,9 & 6,5 \\
\hline Норвегия & 1,3 & 3,0 & 5,6 \\
\hline Дания & 2,1 & 4,1 & 8,2 \\
\hline Великобритания & 2,0 & 4,6 & 7,8 \\
\hline Нидерланды & 2,3 & 5,5 & 10,2 \\
\hline Бельгия & 2,7 & 6,0 & 10,3 \\
\hline Франция & 1,0 & 7,5 & 7,1 \\
\hline Германия & 3,2 & 5,0 & 9,3 \\
\hline Австрия & 2,1 & 5,7 & 8,1 \\
\hline Швейцария & 2,2 & 5,7 & 6,9 \\
\hline Греция & 2,5 & 4,7 & 5,4 \\
\hline Италия & 1,5 & 2,6 & 3,7 \\
\hline Испания & 0,7 & 2,3 & \\
\hline
\end{tabular}

все эксперты сходятся во мнении, что численность приверженцев ислама в европейских странах будет только возрастать, причём такими темпами, что в некоторых городских ареалах и регионах в обозримой перспективе мусульмане станут большинством.

По данным Pew Research Center мусульманское население Европы (включая Россию) возрастёт с 44,1 млн. в 2010 г. до 58,2 млн. в 2030 г. ${ }^{2}$ Основной прирост му-

\footnotetext{
${ }^{1}$ The Future of the Global Muslim Population Projections for 2010-2030 // Pew Research Centre. - URL: http://pewforum.org.

${ }^{2}$ Там же.
}

На первый взгляд, представленные выше цифры не свидетельствую о неминуемой угрозе исламизации европейского пространства. Действительно, численность мусульман в европейских странах (за исключением Балкан) сейчас составляет не более 7-8\% всего населения, и по прогнозам в ближайшие двадцать лет не превысит 10-11\%. Однако важнейшей особенностью расселения мусульман в Европе является их сильная

\footnotetext{
${ }^{3}$ The Future of the Global Muslim Population Projections for 2010-2030 // Pew Research Centre. - URL: http://pewforum.org.

${ }^{4}$ Там же.
} 
концентрация на определённых территориях, в частности в крупных городах. Так более чем в десяти европейских городах проживает свыше 100 тыс. мусульман. В Лондоне их 650 тыс. (8\% населения), в Париже - около миллиона (12\%), в Брюсселе мусульмане составляют около 20\% населения, а в Бирмингеме и Роттердаме на них уже приходится почти половина населения 5 .

Рост численности и доли мусульман в населении европейских стран обусловлен не только притоком новых иммигрантов, но и естественным приростом. Высокий уровень рождаемости и особенности возрастной структуры мусульманского населения, в которой доля пожилых людей относительно невелика, предопределяют бурный рост мусульманской общины и без иммиграционной «подпитки». На диаграмме 1 показано соотношение уровня воспроизводства мусульманского и немусульманского населения некоторых европейских стран. Превышение уровня фертильности среди мусульман наблюдается во всех европейских странах, достигая максимальных значений в странах Северной Европы. В целом мусульманские женщины в Европе рожают на одного ребёнка больше, чем «христианки». При таком уровне рождаемости, даже без притока извне, каждое последующее поколение европейских мусульман будет на треть больше предыдущего, в то время как «христиан» с каждым поколение будет становиться на четверть меньше.

В чём же заключается причина появления и столь конфликтного существования в Европе мусульманского сообщества? Попробуем посмотреть на причины этого явления.

После французской революции 1789 г., послужившей отправной точкой распространения либеральной и социалистической идеологий, европейские страны стали постепенно, шаг за шагом, отказываться от своих традиционных религиозных ценностей и мировоззрения. Этот отказ не всегда был заметным для рядового обывателя, но, безусловно, поступательным и неуклонным. Таким образом, ко второй половине XX века, началу массового притока мигрантов-мусульман, Европа пришла практически полностью утратив значение христианских догматов в общественном сознании, а, также потерпев идеологический и моральный крах в двух мировых войнах, утратив желание и возможность играть главенствующую геополитическую роль в мире.

Диаграмма 1.

Коэффициент фертильности мусульманского и немусульманского населения некоторых европейских стран, 2005-2010 г2. ${ }^{6}$

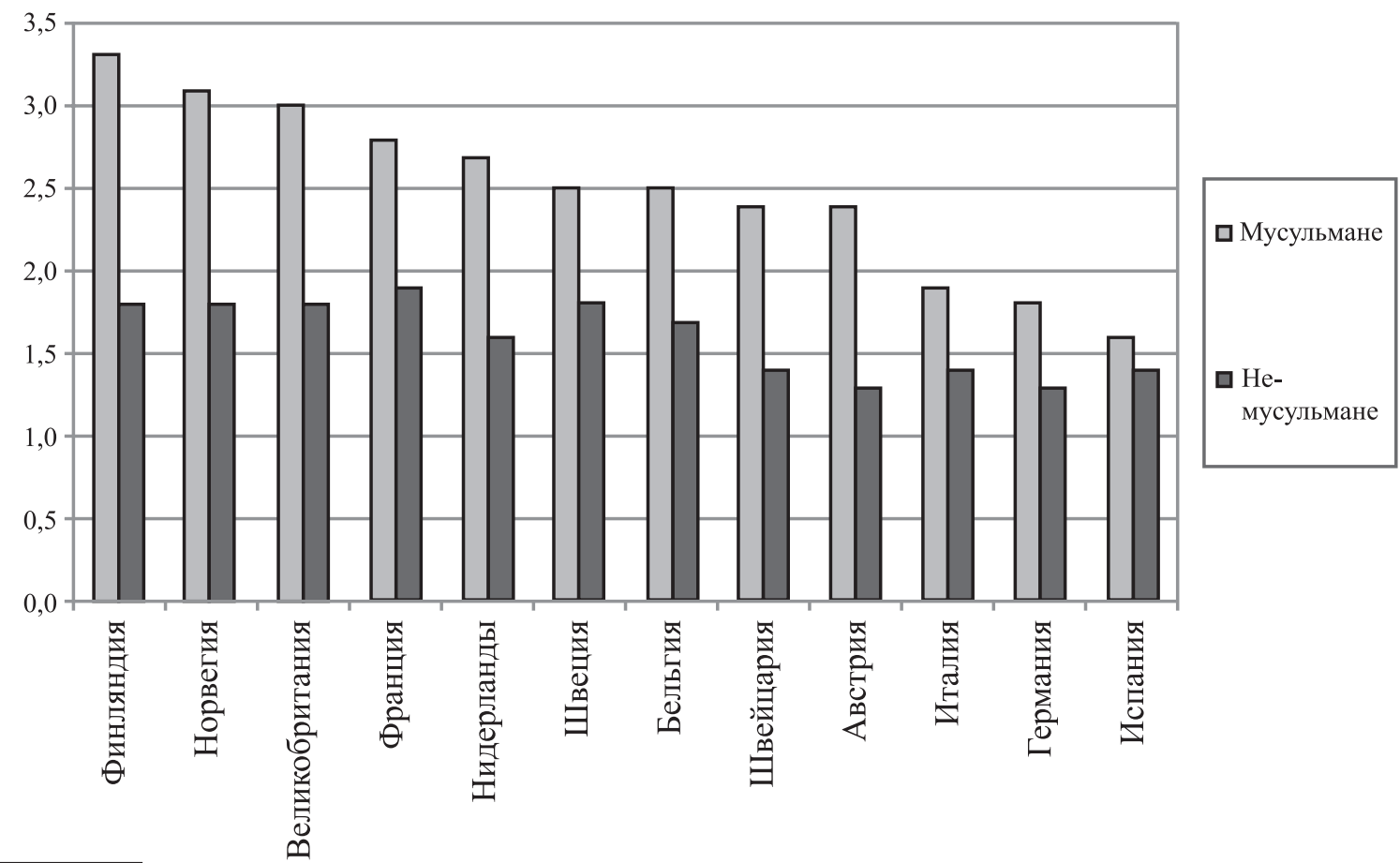

${ }^{5}$ Кошкаров А., Сумленный С. Теперь здесь ислам // Эксперт. - 2008. - № 38. - URL: http://expert.ru/printissues/ expert/2008/38/teper_zdes_islam/.
${ }^{6}$ The Future of the Global Muslim Population Projections for 2010-2030 // Pew Research Centre. - URL: http://pewforum.org. 


\section{Политика и общество 4 (100) • 2013}

Фактическая дехристианизация Европы приобрела не только социально-политическое и культурное значение, она выразилась и в демографическом аспекте - замедлении, остановке естественного прироста «коренного» населения, а теперь и масштабной его депопуляции, т.е. постепенному исчезновению «коренных» этнических групп населения. Разумеется, естественным ответом на сокращение населения и, как следствие, дефицит трудовых ресурсов, стало массовое привлечение трудоспособных иммигрантов из стран Азии и Африки. Именно в такой последовательности необходимо рассматривать события, чтобы определить причинно-следственные связи возникновения сегодняшней проблемы «исламизации» Европы.

В обывательских и даже экспертных кругах преобладает мнение, что мусульмане и другие иноэтничные мигранты появились в Европе в результате естественного процесса. Сторонники такого подхода считают, что уровень жизни в Европе выше, чем в Африке и Азии, и поэтому жители бедных стран стремятся попасть туда любой ценой. На первый взгляд, это мнение достаточно обоснованно. Однако почему же выходцы из слаборазвитых стран не приезжали в Европу, например в XIX веке или даже в первой половине XX? Ведь разрыв в уровне экономического развития, скажем, Италии и Эфиопии в конце XIX и конце XX веков не сильно изменился, если даже не стал меньшим. Да и уровни социально-экономического развития современной Турции и Германии несравнимо меньше отличаются, чем разница в экономическом состоянии этих стран столетие назад.

Несмотря на то, что пропасть в экономическом развитии европейских стран и стран с мусульманским населением за последние столетия не увеличилась, ни какой мусульманской иммиграции в Европу в XIX и первой половине XX века не наблюдалось. Наоборот, в то время европейские страны сами были активными донорами населения, «отдав» за океан десятки миллионов человек. Исходя из этого, неоспоримым выглядит вывод о том, что мусульмане в Европе появились не просто в силу более высокого уровня жизни в европейских странах и притяжения людей из бедных регионов мира. Приток мусульманских иммигрантов обусловлен демографическим фактором, а именно отказом от стандарта многодетной семьи вследствие секулярной революции в Европе.

В выступлениях некоторых европейских политиков часто можно услышать о противопоставлении мусульман «христианской» Европе. При этом, употребляя термин «христиане» они часто забывают о несоответствии этого понятия его первоначальному смыслу. Действительно при проведении переписей населения или социологических опросов большинство населения европейских стран идентифицирует себя как «христиане». Однако вместе с этим, в реальной жизни мы видим иную картину. Регулярно посещает церковь и молится лишь незначительная часть так называемых «христиан». Католические и протестантские церкви в Европе либо пустуют и постепенно закрываются, перепрофилируясь например в склады, либо, если они представляют историческую и культурную ценность, становятся объектом интереса туристов ${ }^{7}$.

Даже в ещё недавно твердых «бастионах» католицизма - Испании, Ирландии, Польше и некоторых других странах за последние десятилетия церковь потеряла огромную часть своего влияния и авторитета, а самое главное умы и души рядовых прихожан. В этом ряду показательным является пример Польши, в которой католическая церковь после падения коммунизма, для краха которого она сделала так много, постепенно утрачивает свои позиции.

В современном лексиконе социологов и политологов термины «христиане» и «христианский» употребляются совсем не в том значении, в котором эти понятия рассматривали, скажем, первые христиане. Как замечает игумен Филарет (Булеков) «сознательные, подлинно церковные христиане в Европе - это меньшинство» ${ }^{8}$.

Именно отсюда проистекают корни проблемы «исламизации» Европы. Если бы Европа не отказалась от своей христианской веры и роли церкви в общественной жизни, то и институт семьи не подвергся такой сильной деградации, в которой он пребывает сейчас и, соответственно, ни о каком демографическом кризисе не шло бы и речи.

Сценариев развития сложившейся ситуации, на наш взгляд, несколько. Во-первых, европейцы могут надеяться, что со временем мусульманское население Европы воспримет либеральные ценности, секуляризуется и постепенно интегрируется. В случае если этого не произойдет, европейцы могут оказаться на правах ненужных гостей в собственном доме, достаточно вспомнить опыт Косово.

\footnotetext{
${ }^{7}$ Кошкаров А., Сумленный С. Теперь здесь ислам // Эксперт. - 2008. - № 38. - URL: http://expert.ru/printissues/ expert/2008/38/teper_zdes_islam/.

${ }^{8}$ Игумен Филарет (Булеков). Время новой проповеди // Эксперт. - 2011. - № 2 (736). - С. 95.
} 
DOI: $10.7256 / 1812-8696.2013 .04 .11$

Миграция и адаптация

Второй выход, состоит в попытках ограничить приток новых иммигрантов, направив максимум усилий на интеграцию уже находящихся в Европе мусульман. Однако полностью отказаться от приёма мигрантов в нынешней демографической ситуации европейские страны просто не могут и, кроме того, уже находящееся в Европе мусульманское сообщество будет расти и без подпитки извне, благодаря более высокому естественному приросту.

Третий возможный сценарий - это пролонгирование существующих демографических и политических тенденций до определённой критической точки, после которой произойдёт геноцид той или иной стороны.

Четвёртый сценарий - возвращение христианских религиозных ценностей в массовое общественное сознание «коренных» европейцев, изменение жизненных приоритетов людей, с переориентацией на традиционную семью. Как следствие - коренное и долгосрочное улучшение демографической ситуации, и по этой причине, отказ от приёма иммигрантов.

Кроме того, в случае ренессанса христианской религии в Европе может быть снята и конфликтность в отношениях с уже существующей мусульманской частью населения. История знает немало примеров мирного сосуществования представителей христианской и мусульманской конфессий даже в «тёмном» средневековье. В конце концов, сами мусульманские религиозные постулаты говорят о возможности сожительства с представителями иных монотеистических религий, и, наоборот, о необходимости беспощадной борьбы с безбожием. Уже цитируемый нами игумен Филарет развивает эту мысль ещё больше, считая что «все подлинно религиозные люди и общины, например христиане и мусульмане, - союзники в противостоянии агрессивному секуляризму, игнорирующему сущностные особенности религиозной веры и навязывающему всем и каждому сугубо секулярные принципы»?.

Вернёмся всё же к демографическому аспекту рассматриваемой проблемы. О возможности серьёзного улучшения демографической ситуации в европейских странах (в том числе и в постсоветских государствах) в случае возрождения христианства, свидетельствует опыт и некоторых других высокоразвитых стран, например Израиля и США.

Уровень религиозности в Израиле необычайно высок для экономически высокоразвитой страны.

\footnotetext{
${ }^{9}$ Игумен Филарет (Булеков). Время новой проповеди // Экс-
} перт. - 2011. - № 2 (736). - С. 95.
Причём эта религиозность наблюдается не только среди еврейского населения страны, но и среди христиан, друзов и, разумеется, мусульман. В Израиле на одну женщину в среднем приходится 2,8 детей (для сравнения в европейских странах этот показатель в два раза ниже) ${ }^{10}$. Высокая рождаемость в еврейских семьях, особенно среди ортодоксов, практически исключает на ближайшие десятилетия возможность исламизации Израиля, которой ещё недавно опасался политический класс этой страны.

Значительно выше среднеевропейского, находится показатель фертильности (воспроизводства населения) и в США - 2, $1^{11}$. Достигается он во многом благодаря более высокому уровню рождаемости в южных штатах, уровень религиозности в которых самый высокий в стране. По данным Pew Research Center, cpeди штатов с наибольшей долей людей, верящих в Бога лидируют Миссисипи (91\%), Южная Каролина (86\%), Алабама (86\%), Теннеси (84\%), Арканзас (84\%), при среднеамериканском уровне $71 \%{ }^{12}$. Причём уровень религиозности населения в США не номинальный, как в Европе и России (о чём будет сказано ниже), а вполне реальный. Так, например, молится, по меньшей мере, раз в день 58\% американцев ${ }^{13}$. Как отмечает С. Хантингтон «американцы - одни из самых религиозных людей на Земле, и этим они сильно отличаются от представителей большинства других промышленно развитых государств» ${ }^{14}$.

Безусловно, уровень рождаемости в 2,1 ребёнка на женщину также обеспечивает всего лишь простое воспроизводство населения, однако с поистине катастрофическими показателями европейских стран ситуация в Америке выглядит вполне удовлетворительной. Следует также отметить, что уровень социальной защищённости в США гораздо ниже, чем практически в любой европейской стране (достаточно вспомнить отсутствие всеобщего медицинского страхования). Тем не менее, на рождаемость в Европе высокие социальные гарантии не влияют. Разумеет-

\footnotetext{
${ }^{10}$ United Nation World Population Prospects: The 2008 Revision Population. - URL: http://esa.un.org/unpp/p2k0data.asp.

11 Там же.

${ }^{12}$ How Religious Is Your State? // Pew Research Centre. - URL: http://pewforum.org/How-Religious-Is-Your-State-.aspx.

${ }^{13}$ How Religious Is Your State? // Pew Research Centre. - URL: http://pewforum.org/How-Religious-Is-Your-State-.aspx.

${ }^{14}$ Хантингтон С. Кто мы?: Вызовы американской национальной идентичности. - М.: АСТ, 2004. - С.145.
} 


\section{Политика и общество 4 (100) • 2013}

ся, это не означает, что европейские страны должны урезать уровень социальных гарантий и поддержки материнства, но политические силы, особенно в левом политическом спектре, должны прекратить риторику о возможности роста рождаемости при увеличении уровня жизни населения.

Практически весь опыт развития демографических процессов показывает зависимость уровня рождаемости от сохранения традиционных (религиозных) семейных ценностей, а также уровня урбанизации. В противоположность им, материальная и экономическая стимуляция рождаемости не даёт ощутимых результатов.

Итак, корень современных демографических, культурных и политических проблем европейского континента лежит, прежде всего, в грандиозном процессе дехристианизации последних двух столетий. Такие явления как «исламизация», параллельные сообщества иммигрантов, демографический кризис и общее ослабление геополитической и цивилизационной роли Европы, возникли в результате отказа от христианских ценностей, распространения идеологии эгоизма, и приоритета прав личности. Выходов у Европы из этой ситуации, по сути, только два, или возвращение к своим историческим, религиозным и культурным корням, или постепенная деградация и вымирание уже в пределах жизни одного-двух поколений.

В заключение отметим, что проблемы «исламизации», перераспределения этнической структуры населения, роста ксенофобии характерны и для России. Несмотря на определённые исторические особенности, иную общественно-политическую ситуацию в стране, Россия, в целом, находится в контексте общеевропейских социальных трансформаций.

Возрождение общественной роли церкви, рост её авторитета и политического влияния, а также номинального числа прихожан Русской православной церкви (РПЦ) за последние два десятилетия, привёл к иллюзии возрождения в обществе традиционных христианских ценностей. Однако эмпирические социологические данные демонстрируют иные факты.

По данным ВЦИОМ 2010 года 86\% жителей России считает себя верующими людьми (75\% - называют себя приверженцами православия, 5\% - ислама), что для страны пережившей в XX веке религиозную катастрофу достаточно впечатляющий результат ${ }^{15}$. Однако,

\footnotetext{
${ }^{15}$ Верим ли мы в Бога?: пресс-выпуск ВЦИОМ № 1461 от 30 мар-
} та 2010 г. - URL: http://wciom.ru/index.php?id=268\&uid=13365. при этом, из общего числа «верующих» молится только $7 \%$, а «соблюдает все заповеди» $2 \%$ опрошенных ${ }^{16}$. Эти цифры, на наш взгляд, гораздо объективнее отражают современное состояние духовных ценностей в России.

Публичная принадлежность к православию в современной России в значительной мере превратилась в определённый стандарт, моду. Причислять себя к христианской церкви стало общественной нормой, примерно такой же какой в советский период было не менее единодушное отрицание религии. Однако на фоне такого общественного религиозного «стандарта», истинно верующих людей в стране считанные проценты.

Отдельно следует отметить, что рост влияния РПЦ в последнее время, особенно после избрания патриарха Кирилла, не решает вопроса распространения христианских ценностей в обществе. Скорее наоборот, срастание церковной и светской власти в глазах общественности приводит к перекладыванию определённой доли ответственности (и латентного недовольства) за состояние страны «на плечи» РПЦ.

Таким образом, возрождение Русской православной церкви не привело к возрождению христианских ценностей в России, и перспективы такого возрождения по-прежнему туманны.

Физическим следствием духовно-нравственного кризиса в современной России стала демографическая катастрофа. Демографические расчёты показывают, что основной причиной роста рождаемости, в последние годы, стали не усилия правительства по улучшению демографической ситуации, а особенности возрастной структуры населения страны. Вступление в активный детородный период многочисленного поколения людей, родившихся в 1980-е годы, естественным образом повысило рождаемость. Однако уже к середине наступившего десятилетия в возраст рождения первого ребёнка вступит практически вдвое меньшее поколение, родившихся в 1990-е годы, и тогда демографический кризис вновь даст о себе знать, ежегодно уменьшая население России на 500-1000 тыс. человек в год ${ }^{17}$.

Рассчитывать на возможность роста рождаемости в результате увеличения социальных выплат государства не приходится. По данным ФОМ даже в случае нали-

\footnotetext{
${ }^{16}$ Верующих в России много, воцерковлённых - значительно меньше: пресс-выпуск ВЦИОМ № 1465 от 5 апреля 2010 г. URL: http://wciom.ru/index.php?id=268\&uid=13385.

${ }^{17}$ United Nation World Population Prospects: The 2008 Revision Population. - URL: http://esa.un.org/unpp/p2k0data.asp.
} 
чия «идеальных условий» только около трети опрошенных россиян заявляют о желании иметь трёх и более детей, и примерно 40\% заявляют о желании иметь двух детей ${ }^{18}$. Таким образом, материальное стимулирование рождаемости может дать только незначительный её рост. Не следует также забывать и о «качестве» воспитания детей, рождённых за деньги государства.

Преодолеть демографический кризис европейские страны и Россия могут только кардинально увеличив средний стандарт семьи с одно-двухдетной до, минимум, двух-трёхдетной. Добиться этого, можно изменив духовно-нравственную ситуацию в обществе, возродив христианские ценности в европейском социальном и культурном пространстве.

\section{Библиография:}

1. Бездетность и нежелание иметь детей [Электронный ресурс] // Фонд общественное мнение [офиц. сайт] / Фонд «Общественное мнение». - М., 2003-2011. URL: http://bd.fom.ru/report/cat/socium/demo/d082125.

2. Верим ли мы в Бога?: пресс-выпуск ВЦИОМ № 1461 от 30 марта 2010 г. [Электронный ресурс] // ВЦИОМ [офиц. сайт] / Всероссийский центр изучения общественного мнения. - M., 2000-2012. - URL: http://wciom.ru/index.php?id=268\&uid=13365.

3. Верующих в России много, воцерковлённых - значительно меньше: пресс-выпуск ВЦИОМ № 1465 от 5 апреля 2010 г. [Электронный ресурс] // ВЦИОМ [офиц. сайт] / Всероссийский центр изучения общественного мнения. - M., 2000-2012. - URL: http://wciom.ru/index.php?id=268\&uid=13385.

4. Игумен Филарет (Булеков). Время новой проповеди [Текст] / Игумен Филарет (Булеков) // Эксперт. - 2011. - № 2 (736). - С. 93-95.
5. Кошкаров А. Теперь здесь ислам [Электронный pecypc] / А. Кошкаров, С. Сумленный // Эксперт. - 2008. - № 38 (627). URL: http://expert.ru/printissues/expert/2008/38/teper_zdes_islam/.

6. Хантингтон С. Кто мы?: Вызовы американской национальной идентичности [Текст] / [пер. с англ.] / С. Хантингтон. - М.: АСТ, 2004. - 635 с. ISBN 5-17-024800-8.

7. How Religious Is Your State? [Electronic resource] // Pew Research Centre / Pew Research Centre. Washington, 2012. - URL: http://pewforum.org/ How-Religious-Is-Your-State-.aspx.

8. The Future of the Global Muslim Population Projections for 2010-2030. [Electronic resource] // Pew Research Centre / Pew Research Centre. - Washington, 2012. - URL: http://pewforum.org.

9. United Nation World Population Prospects: The 2008 Revision Population Database [Electronic resource] // United Nation / Department of Economic and Social Affairs. - New York, 2012. - URL: http://esa. un.org/unpp/p2k0data.asp.

\section{References (transliteration):}

1. Igumen Filaret (Bulekov). Vremya novoy propovedi [Tekst] / Igumen Filaret (Bulekov) // Ekspert. - 2011. - № 2 (736). - S. 93-95.

2. Koshkarov A. Teper' zdes' islam [Elektronnyy resurs] / A. Koshkarov, S. Sumlennyy // Ekspert. - 2008. - № 38 (627). URL: http://expert.ru/printissues/expert/2008/38/teper_zdes_islam/.

3. Khantington S. Kto my?: Vyzovy amerikanskoy natsional'noy identichnosti [Tekst] / [per. s angl.] / S. Khantington. - M.: AST, 2004. - 635 s. - ISBN 5-17-024800-8.

18 Бездетность и нежелание иметь детей: ФОМ от 29 мая 2008 г. - URL: http://bd.fom.ru/report/cat/socium/demo/d082125. 